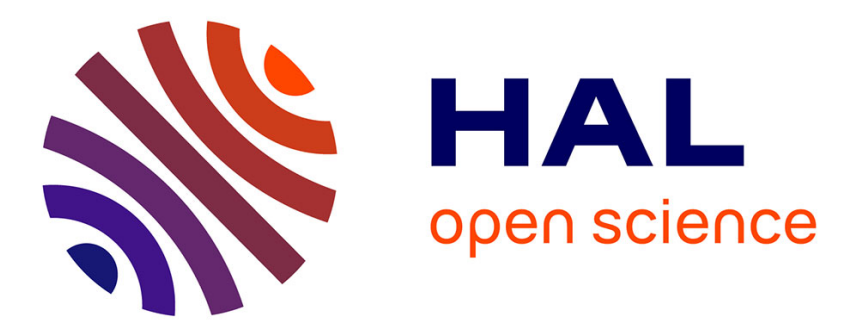

\title{
Umbrella Structure in Pr, Nd and Yb Substituted YIG Studied by $57 \mathrm{Fe}$ NMR
}

J. Englich, J. Kohout, H. Stepánková, P. Novák, M. Nekvasil, H. Lütgemeier

\section{To cite this version:}

J. Englich, J. Kohout, H. Stepánková, P. Novák, M. Nekvasil, et al.. Umbrella Structure in Pr, Nd and Yb Substituted YIG Studied by 57Fe NMR. Journal de Physique IV Proceedings, 1997, 07 (C1), pp.C1-295-C1-296. 10.1051/jp4:19971117 . jpa-00254757

\section{HAL Id: jpa-00254757 https://hal.science/jpa-00254757}

Submitted on 1 Jan 1997

HAL is a multi-disciplinary open access archive for the deposit and dissemination of scientific research documents, whether they are published or not. The documents may come from teaching and research institutions in France or abroad, or from public or private research centers.
L'archive ouverte pluridisciplinaire HAL, est destinée au dépôt et à la diffusion de documents scientifiques de niveau recherche, publiés ou non, émanant des établissements d'enseignement et de recherche français ou étrangers, des laboratoires publics ou privés. 


\title{
Umbrella Structure in Pr, Nd and Yb Substituted YIG Studied by ${ }^{57} \mathrm{Fe}$ NMR
}

\author{
J. Englich, J. Kohout, H. Stł́pánková, P. Novák*, M. Nekvasil* and H. Lütgemeier** \\ Faculty of Mathematics and Physics, Charles University Prague, V. Holesovickách 2, 18000 Prague 8 , \\ Czech Republic \\ * Institute of Physics, Cukrovarnická 10, 16200 Praha 6, Czech Republic \\ ** EFF, KFA Jülich, 52425 Jülich, Germany
}

\begin{abstract}
The NMR spectra of ${ }^{57} \mathrm{Fe}$ in Pr: $\mathrm{YIG}, \mathrm{Nd}: \mathrm{YGG}$ and $\mathrm{Yb}$ : $\mathrm{YIG}$ were measured on polycrystalline samples at $4.2 \mathrm{~K}$ in the zero external field. In the NMR spectra of both tetrahedral and octahedral sites the resolved satellite structure appears. This structure is caused by the change of the hyperfine field on the nuclei of those $\mathrm{Fe}^{3+}$ ions, which are the nearest or next nearest neighbours of the substituted $\mathrm{Re}^{3+}$ ion. The change of the hyperfine field is given by the change of dipole and transferred contribution. Both contributions are sensitive to the kind of $\mathrm{Re}^{3+}$ ion and to the value and direction of its magnetic moment. The satellite structure of NMR spectra provides sufficient amount of information (splitting) to find unknown parameters of the non-collinear (umbrella) arrangement of $\mathrm{Re}^{3+}$ magnetic moments.
\end{abstract}

Yttrium iron garnet $\left(\mathrm{Y}_{3}\right)_{\mathrm{e}}\left\{\mathrm{Fe}_{2}\right\}_{d}\left[\mathrm{Fe}_{3}\right]_{\mathrm{a}} \mathrm{O}_{12}$ (VIG) is one of the often studied ferrimagnetic cubic oxides. There are three types of cation lattice sites in YIG. Fe ${ }^{3+}$ ions occupy trigonal distorted octahedral a-sites with the symmetry axis along the [111] direction and tetragonally distorted tetrahedral d-sites having the symmetry axis along the [100] direction. The local symmetry of dodecahedral c-sites occupied by $\mathrm{Y}^{3+}$ ions is orthorhombic and there are six c-sites in the unit cell with the different orientation of the local co-ordinate system.

The principal magnetic interaction in YIG is the superexchange in the $\left(\mathrm{Fe}^{3+}\right)_{\mathrm{d}}-\mathrm{O}^{2-}-\left(\mathrm{Fe}^{3+}\right)_{\mathrm{a}}$ triads. This interaction forms two antiparallel iron sublattices with the easy axis along the [111] direction. In rare earth substituted systems $\left(\mathrm{Y}_{3-x} \mathrm{Re}_{\mathrm{x}}\right)_{c}\left\{\mathrm{Fe}_{2}\right\}_{d}\left[\mathrm{Fe}_{3}\right]_{\mathrm{a}} \mathrm{O}_{12}$ (Re:YIG) reported in this paper the easy axis keeps the [111] direction of $\mathrm{YIG}$.

Magnetic moments of Re-cations in Re:YIG have at most six different magnitudes and directions if the magnetization lies in the general direction. If the magnetization lies in the [111] direction (in zero external field) there exist two groups of three magnetically equivalent $c$ sites (c, $\left.c^{\prime}\right)$ [1]. Re-magnetic moments lie in the planes of the (110) type, forming so called umbrella structure [1] described by magnitudes ( $\left.m, m^{\prime}\right)$ of Re-moments and umbrella angles $(\varphi$, $\left.\varphi^{\circ}\right)$. Umbrella angles are measured from [111]. In our notation the angle is positive when turning from [111] to [112] in the (110) plane and similarly in other planes of the (110) type.

The ${ }^{57} \mathrm{Fe}$ NMR spectrum in the stoichiometric YIG consists of three lines corresponding to $\mathrm{Fe}^{3+}$ ions in $\mathrm{d}$-sites and two magnetically inequivalent $\mathrm{a}_{1}$ - and $\mathrm{a}_{2}$-sites [2]. When a small amount of $\mathrm{Y}^{3+}$ ions is replaced by $\mathrm{Re}^{3+}$ ions, characteristic satellite structure in the NMR spectrum appears. This structure is caused by the change of the hyperfins field on the nuclei of $\mathrm{Fe}^{3+}$ ions which have the $\mathrm{Re}^{3+}$ ion in the first or second neighbourhood. Re-ions in the third and oiher environments contribute to the line broadening oniy (in our region of Re-concentration). The value of the syliting is sensitive to the ionic radius of the $\mathrm{Re}^{3+}$ ion, to the magnitude and orientation of its magnetic moment and to its position in the vicinity of the given $\mathrm{Fe}^{3+}$ ion.

In this paper we present the values of Re-magnetic moments and umbrella angles obtained from the analysis of ${ }^{57} \mathrm{Fe}$ NMR spectra in Pr:YIG $(x=0.1)$, Nd:YIG $(x=0.35)$ and $Y b: Y I G(x=0.1)$

Our NMR experiments were performed on the polycrystalline samples prepared by the conventional ceramic technology and sintered at about $1450^{\circ} \mathrm{C}$. The phase purity and homogeneity was checked by X-rays. Concentration of Re was given by the technology and checked by the atomic spectroscopy and by the amplitude of satellites. The estimated error in $x$ was of the order of 0.01 .

NMR spectra were measured by the spin echo technique at $4.2 \mathrm{~K}$. The phase cokerent spectrometer with averaging technique and complex Fourier Iransformation was used. As the NMR line splitting is small comparco with the frequency of the main lines, no frequency corrections were made. Relative accuracy of the amplitude in the NMR spectrum is then better than 5\%. All spectra were measured with sufficiently high rf-power to excite the domain signal only. Examples of the NMR spectra normalised to 100 are shown in the Fig. 1.

To fit the satellite structure, we bave supposed the independent and additive contribution of each Re-defect, the ratidom distribution of defects in the $\mathrm{c}-\mathrm{s}$ : $c$ '-sites and the same shape of the main and satellite lines.

The spliting between the main l ie and satellites $\left(\Delta v_{\exp }\right)$ at low temperatures can be written as a sum of three contributions [3]: $\Delta v_{\mathrm{exp}}=\Delta v_{\mathrm{c}}+\Delta v_{\mathrm{pol}}+\Delta v_{\text {dip }}$. The change of the crystal environment contribution ( $\left.\Delta v_{\mathrm{c}}\right)$, independent of 

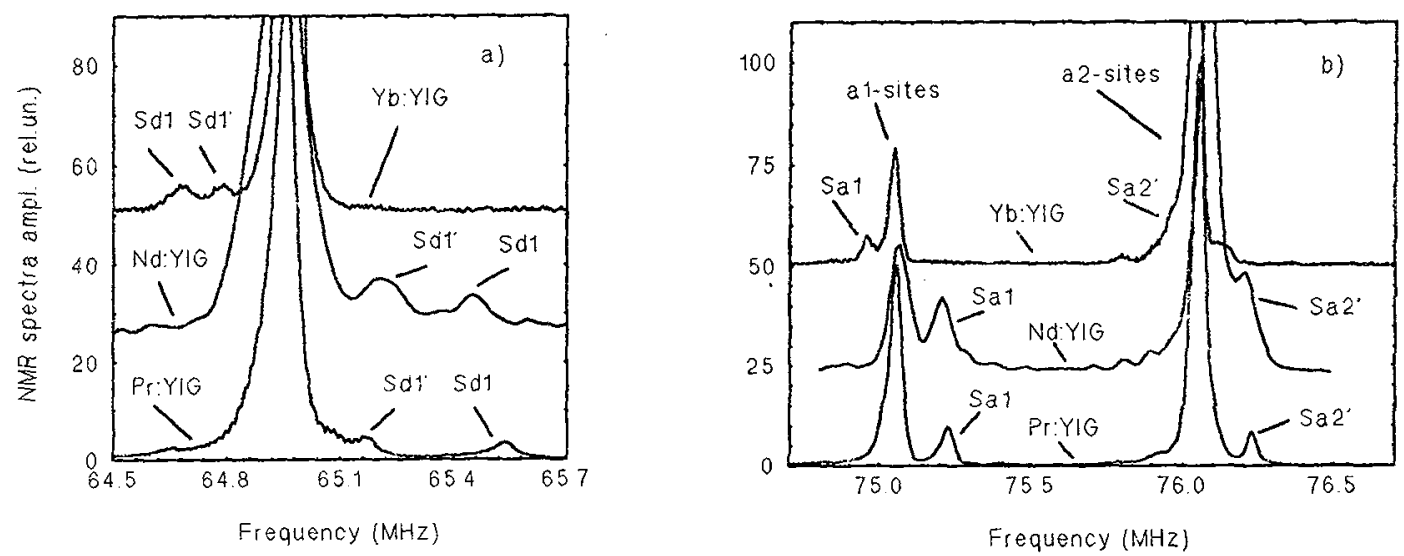

Figure 1: NMR spectra of ${ }^{57} \mathrm{Fe}$ in Re: $\mathrm{YG}$, at $4.2 \mathrm{~K}, \mathrm{~B}_{\mathrm{cx}}=0$. a) d-sites, b) $\mathrm{a}_{1}$ - and $\mathrm{a}_{2}$ - sites.

the Re-magnetic moment, was determined using the linear dependence of $\Delta \mathrm{v}_{\mathrm{c}}$ on the ion radius $\mathrm{c} R \mathrm{Re}^{3+}$ in the eight-fold co-ordination [3], [4]. To determine the polarised part of the crystal environment contribution ( $\left.\Delta v_{\text {pol }}\right)$, it was supposed, that this contribution is proportional to the projection of the total $\mathrm{Re}^{3+}$-spin on the direction of the $\mathrm{Re}^{3+}$-magnetic moment. Using the value of $\Delta v_{\mathrm{pol}}(\mathrm{Gd})$, determined from the temperature dependence of the NMR spectra in Gd:YGG [5], we can calculate: $\Delta v_{\mathrm{pol}}(\mathrm{Re})=-\Delta v_{\mathrm{pol}}(\mathrm{Gd}) \mathrm{m} \cdot \cos \varphi \cdot\left(\mathrm{g}_{\mathrm{y}}-1\right) / 3.5 \mathrm{~g}$ ([3], [4]). The dipolar contribution $\left(\Delta v_{\mathrm{dp}}\right)$ is given by the projection of the dipolar field on the direction of the ${ }^{57} \mathrm{Fe}$ hyperfine field and can be calculated $\Delta v_{\text {dip }}$ using the lattice structure data and two pairs of unknown umbrella parameters $(\mathrm{m}, \varphi)$ and $\left(\mathrm{m}^{\prime}, \varphi^{\natural}\right)$.

To find these parameters we need at least two pairs of independent splitting in the NMR spectrum. In our case we have used two well rescluted satellites of the d-line $\left(s_{\mathrm{d} 1}, s_{\mathrm{dl}}{ }^{\prime}\right)$ and the satellites of the $\mathrm{a}_{1}$ - and $\mathrm{a}_{2}$-lines $\left(\mathrm{s}_{\mathrm{a} 1}, \mathrm{~s}_{\mathrm{a} 2}{ }^{\prime}\right)$ which correspond to the substitution of the $\mathrm{Re}^{3+}$ in the ncarest $\mathrm{c}\left(\mathrm{c}^{\prime}\right)$ - sites of the given $\mathrm{d}$ - or a-site respcctively. The results are summarised in the Table 1. Since we can not determine with confidence which of the d-line satellites belongs to the c- or $c$ '-site, we have calculated two sets of umbrella parameters. To distinguish between these two sets the higher resulution in

\begin{tabular}{|c|c|c|c|c|c|c|}
\hline $\mathrm{Re}$ & $m\left(\mu_{E}\right)$ & $\varphi\left(0^{\circ}\right)$ & $m^{\prime}\left(\mu_{B}\right)$ & $\left\langle p^{\circ}\left(0^{\circ}\right)\right.$ & $m[111] N M R$ & $\mathrm{~m}[111]_{\text {maxns. }}[$ Ref.] \\
\hline $\operatorname{Pr}$ & $\begin{array}{l}2.5(2) \\
3.1(3) \\
\end{array}$ & $\begin{array}{r}9(3) \\
-40(8) \\
\end{array}$ & $\begin{array}{l}3.4(3) \\
2.7(3) \\
\end{array}$ & $\begin{array}{r}-36(5) \\
8(3) \\
\end{array}$ & $\begin{array}{l}2.6(3) \\
2.6(3)\end{array}$ & $\begin{array}{ll}1.53 & {[8]}\end{array}$ \\
\hline $\mathrm{Nd}$ & $\begin{array}{l}1.8(2) \\
1.7(2)\end{array}$ & $\begin{array}{r}19(5) \\
-13(4) \\
\end{array}$ & $\begin{array}{l}0.9(2) \\
1.2(2)\end{array}$ & $\begin{array}{r}-12(3) \\
40(5) \\
\end{array}$ & $\begin{array}{l}1.3(2) \\
1.3(2)\end{array}$ & 1.65 \\
\hline$Y b$ & $\begin{array}{l}2.0(2) \\
2.0(2) \\
1.7 *\end{array}$ & $\begin{array}{l}217(5) \\
220(5) \\
186^{*}\end{array}$ & $\begin{array}{l}1.7(2) \\
1.6(2) \\
1.7 *\end{array}$ & $\begin{array}{l}232(5) \\
227(5) \\
187^{*}\end{array}$ & $\begin{array}{l}1.3(3) \\
1.3(3)\end{array}$ & $\begin{array}{c}1.67 \quad[8] \\
*[9]\end{array}$ \\
\hline
\end{tabular}

the NMR spectra (lower Re concentration) is necessary to see two other satellites of the $a_{2}$-line $[2]$, or the second nearest neighbour satellite of the $a_{1}$-line [3].

The mean magnetic moments along the [111] direction deduced from the NMR data (m[111 $]_{\mathrm{NMR}}$ ) for $\mathrm{Nd}^{3+}$ and $\mathrm{Yb}^{3+}$ in YIG compare favourably with the values deduced from the saturation magnetization (m[111 $]_{\operatorname{mang}}$ ) [6] and infrared spectroscopy [7]. A similar comparison of $\mathrm{Pr}^{3+}$ results shows a considerable discrepancy, which can be tentatively associated with a special nature of the crystal-field (CF) ground state [8]. The quantitative calculations involving the $\mathrm{CF}$ potential and the magnetic exchange interaction Pr-Fe are in progress. These should allow us to decide which of two above mentioned umbrella structures compatible with our NMR data in Pr:YIG is correct.

\section{References}

[1] Tcheou F., Bertant E.F. and Fuess H., Solid State Comm. 8 (1970) 1751

[2] Englich J., Luetgemeier H., Pieper M. W., Novak P. and Nekvasil M., Sol. State. Comm. 56 (1985) 825

[3] Englich J., Kohout J., Novak P., Luetgemeier H., IEEE Trans. Magn. 30 (1994) 972

[4] Doroshev V.D., Savosta M.M. and Novak P., Physica B 189 (1994) 290

[5] Englich J., Novak P., Kuriplach J. and Luetgemeier H., Hyp. Int. 59 (1990) 493

[6] Landoldt-Boernstein, New Series, 27e, O.Madelung and H. P. J. Wijn Eds. (Springer-Verlag, Berlin, 1991) 20

[7] Wickershein K. A and White R. L., Phys. Rev. Lett. 8 (1962) 483

[8] Nekvasil V. and Veltrusky I., J. Magn. Magn. Mater. 86 (1990) 315. 